\title{
Novel dynein axonemal assembly factor 1 mutations identified using whole-exome sequencing in patients with primary ciliary dyskinesia
}

\author{
LEI ZHOU ${ }^{1}$, ZHUOZHE LI $^{2}$, CHUNLING DU ${ }^{1}$, CUICUI CHEN ${ }^{2}$, YINGXIN SUN ${ }^{1}$, \\ LIANG GU $^{1}$, FENG ZHOU ${ }^{1}$ and YUANLIN SONG ${ }^{2}$ \\ ${ }^{1}$ Department of Pulmonary Medicine, Qingpu Branch of Zhongshan Hospital, Shanghai 201700; \\ ${ }^{2}$ Department of Pulmonary and Critical Care Medicine, Zhongshan Hospital, Fudan University, \\ Shanghai 200032, P.R. China
}

Received November 11, 2019; Accepted June 15, 2020

DOI: $10.3892 / \mathrm{mmr} .2020 .11562$

\begin{abstract}
Primary ciliary dyskinesia (PCD) is a rare, genetically heterogeneous disorder caused by dysfunction of the cilia and flagella; however, causative genetic defects have not been detected in all patients with PCD. Seven Chinese Han patients with Kartagener syndrome were enrolled onto the present study. Transmission electron microscopy (TEM) was performed to evaluate the cilial defects and whole-exome sequencing was used to analyze relevant genetic variations in all patients. In two of the seven patients with PCD, four novel dynein axonemal assembly factor 1 (DNAAF1) mutations were identified (NM_178452.6:c.3G $>$ A, c. $124+1 \mathrm{G}>\mathrm{C}$, c.509delG and c.943A $>$ T) in three alleles. Both of these patients had long-standing infertility. Their chest computed tomography results showed bronchiectasis, lung infections and situs inversus, and paranasal computed tomography revealed sinusitis. Semen analysis of the male patient showed poor sperm motility. TEM showed defects in the inner and outer dynein arms in both patients. The $D N A A F 1$ sequences of family members were then analyzed. Bioinformatics analysis indicated that these mutations may be the cause of the cilial defects in these two probands. Thus, the present study identified novel PCD-causing mutations in DNAAFl in two patients with PCD. These genetic variations were predicted to alter DNAAF1 amino acid residues and lead to loss of function, thereby inhibiting cilia-mediated motility. Accordingly, the two probands had PCD symptoms, and one of them died due to PCD-associated complications.
\end{abstract}

Correspondence to: Professor Yuanlin Song, Department of Pulmonary and Critical Care Medicine, Zhongshan Hospital, Fudan University, 180 Fenglin Road, Shanghai 200032, P.R. China

E-mail: song.yuanlin@zs-hospital.sh.cn

Key words: primary ciliary dyskinesia, dynein axonemal assembly factor 1, mutation, exome sequencing, bronchiectasis, situs inversus

\section{Introduction}

Primary ciliary dyskinesia (PCD) is a rare, genetically heterogeneous disorder inherited in an autosomal recessive manner in most cases (1). In half of affected individuals, PCD occurs with situs inversus, which is characterized by the mirror-image reversal of visceral organs, such as the heart, liver and spleen, but without apparent physiological consequences. This condition is referred to as Kartagener syndrome, which is the combination of situs inversus, bronchiectasis, and nasosinusitis (2). The aberrant structure and/or function of motile cilia in the airways, paranasal sinus, inner ear and other organs can prevent motility and may affect mucus clearance in these organs, thus leading to conditions like bronchiectasis, nasosinusitis and otitis. The flagella of sperm are also a type of cilia, therefore flagellar dysfunction decreases the motility of sperm and leads to infertility. The absence of normal nodal ciliary function during embryogenesis can lead to randomized organ placement, which explains why approximately half of affected individuals have situs inversus (3). The estimated prevalence of PCD ranges from 1:2,200 to 1:40,000 in Western countries (1). There is no prevalence data for the Chinese population; however, PCD appears to have a higher incidence compared with cystic fibrosis, which is also a main cause of bronchiectasis, in this population (4). Thus far, 45 genes have been found to be associated to the pathogenesis of PCD (5). These genes encode proteins that contribute to the synthesis or assembly of axonemes, dyneins, radial spokes or other similar structures. Dynein axonemal assembly factor 1 (DNAAF1) primarily affects the preassembly of the inner (IDA) and outer (ODA) dynein arms, which are multisubunit ATPase complexes (6). Mutations in DNAAF1 have been shown to cause PCD (6,7); however, the incidence of DNAAF1 mutations is quite low (7). The present study analyzed clinical and genetic data from seven Chinese patients with PCD. Among these patients, two were found to carry novel DNAAF1 mutations.

\section{Materials and methods}

Patients. Seven Chinese Han patients with Kartagener syndrome (four males and three females; age, 8-41 years; 
median age, 32 years). All of the enrolled patients had chronic cough, excessive sputum production and shortness of breath. The study was approved by the Ethics Committee of Zhongshan Hospital, Qingpu Branch (Shanghai, China) and all participants or their guardians provided written informed consent.

Clinical examination. All patients underwent paranasal and chest computed tomography (CT) and pulmonary function tests. The bronchoscope examination was conducted in one patient and a lung biopsy specimen was acquired. Five of the seven subjects agreed to transmission electron microscopy (TEM) analysis of nasal mucosal cilia or sperm flagella to identify cilial defects. TEM analyses were performed after specimen.preparation. In brief, nasal biopsy specimens obtained from the infraturbinal region and sperm specimens were centrifuged at $2,000 \mathrm{xg}$ for $5 \mathrm{~min}$ at $4^{\circ} \mathrm{C}$. All specimens were fixed in $2.5 \%$ glutaric dialdehyde at room temperature for 2-3 h. After dehydration with alcohol series, samples were embedded in acetonum overnight at room temperature. The solidified specimens were then sliced into 50-60 nm sections and then examined using TEM after double-staining at room temperature with uranyl acetate for $8 \mathrm{~min}$ and lead citrate for 5 min.

Whole-exome sequencing (WES). WES analysis was conducted by Gemple Biotech, and was performed as previously described (8). Genomic DNA was isolated from blood or buccal swab samples for WES or Sanger sequencing. Blood samples were obtained from the peripheral vein. The concentration and integrity of the genomic DNA samples were determined using a Qubit dsDNA HS Assay kit (Thermo Fisher Scientific, Inc.) and by $2 \%$ agarose gel electrophoresis, and visualized with ethidium bromide. Exome sequencing libraries were prepared using the KAPA Hyper Prep kit (Kapa Biosystems; Roche Diagnostics) and enriched using the SeqCapEZ Exome version 3.0 kit (NimbleGen; Roche Diagnostics). Captured libraries were sequenced on an HiSeq platform (Illumina, Inc.), using $150 \mathrm{bp}$ paired-end sequencing.

Variant filtering and bioinformatics analysis. Adapter sequences were removed from the raw data and low-quality reads, containing an excessive number of Ns or having low base quality, were discarded. Sequencing reads were then aligned to the hg19 human reference genome using the Burrows-Wheeler Aligner (version 0.7.15). After further processing in Samtools (version 1.3.1; github.com/samtools/samtools)/Picard (version 2.5; broadinstitute.github.io/picard), the final BAM files were used for variant calling. Single nucleotide polymorphisms and small insertions/deletions were detected using GATK-haplotypeCaller (version 3.6; gatk.broadinstitute. org/hc/en-us). ANNOVAR was then used to annotate the detected variants. The present study focused on previously reported $P C D$-associated genes (4) and found that two probands (patients 1 and 2) carried DNAAF1 (NM_178452.6) mutations. Sanger sequencing was then used to confirm the WES results and analyze the DNAAF1 sequences of the probands' parents. The following primers (Generay Biotech Co., Ltd.) were used for DNAAF1 sequencing: Exon 7, forward: 5'-GTCTGATGC TCACTTTGCTTTGA-3' and reverse: 5'-AAGGAACTCTGG
GGCTGTTGT-3'; exon 1, forward: 5'-GTTGGGCTGTAA AGACTAGGGC-3' and reverse: 5'-TCACTGACTAGCCGA GGGTTA-3'; and exon 4, forward: 5'-TAGGCAAAAACA AGGGTGACCG-3' and reverse: 5'-TGCTGGGTACCCTTA CAGAGG-3'. The DNA polymerase (Taq EXtra) was purchased from Kapa Biosystems. The PCR cycling conditions were as follows: $94^{\circ} \mathrm{C}$ for $25 \mathrm{sec}, 55^{\circ} \mathrm{C}$ for $15 \mathrm{sec}$ and $72^{\circ} \mathrm{C}$ for, $1 \mathrm{~min}$ for 35 cycles. These mutations were then analyzed to predict their functional effects on DNAAF1. SIFT (http://sift.jcvi.org) and PolyPhen-2 (http://genetics.bwh.harvard.edu/pph2) were used to predict the effects of amino acid substitutions, and the Human Splicing Finder (HSF) tool and MaxEnt scan (MES) were used to evaluate splice-site mutations $(9,10)$. AutoPVS1 (http://autopvs1.genetics.bgi.com) was used to interpret the pathogenicity of the variants, according to the refined criteria (PVS1) of the ClinGen Sequence Variant Interpretation Working Group (10). Subsequently, the 1,000 genomes database (www.ncbi.nlm.nih.gov/variation/tools/1000genomes) was searched to identift the frequency of the variations in the healthy population.

\section{Results}

Clinical data for patients PCD with DNAAF1 mutations. The clinical data for all subjects are summarized in Table I. Given that DNAAF1 mutations were found in two probands, a more detailed account of their clinical characteristics are described below.

Proband 1 was a 32-year old, male, non-smoker who had a chronic cough and sputum for over 20 years. He showed recurrent hemoptysis and shortness of breath. He also had a long history of nasosinusitis and primary infertility. Chest CT results showed bronchiectasis in multiple lobes of the lung and situs inversus. Paranasal CT results revealed bilateral maxillary sinusitis and ethmoid sinusitis (Fig. 1A and B). A pulmonary function test yielded the following results: FEV1, 1.80 L/s; FEV1/pred, 53.1\% and FEV1/FVC, 63.43\%, which were significantly decreased compared with healthy individuals. A lung biopsy obtained using a bronchoscope showed bronchiolitis. As few cilia were found in the nasal mucosa biopsy sample, the sperm flagella were analyzed using TEM, demonstrating both IDA and ODA defects (Fig. 2) compared with the normal cilia construction (Fig. 3). The proband's parents were not consanguineous. His mother had a history of asthma, and his father was healthy.

Proband 2 was a 37-year old female non-smoker who was diagnosed with bronchiectasis at 12 years of age. She had a long history of nasosinusitis. Since she was unable to achieve pregnancy naturally for 5 years, she had utilized in vitro fertilization and embryonic implantation using her own ova, which had resulted in healthy twin daughters. She presented with a fever and wheezing when she was admitted. Chest CT results showed bronchiectasis, a severe lung infection and situs inversus. Paranasal CT revealed bilateral maxillary sinusitis, ethmoid sinusitis, sphenoid sinusitis and frontal sinusitis (Fig. 1C and D). Culture of a sputum sample acquired using a bronchoscope showed the presence of an imipenemand cilastatin sodium-resistant Streptococcus viridans infection. Although she agreed to treatment with ceftazidime combined with amikacin and mechanical ventilation through 
Table I. Dynein axonemal assembly factor 1 mutations of the two patients with primary ciliary dyskinesia.

\begin{tabular}{llllll}
\hline Patient no. & Allele & Location & \multicolumn{1}{c}{ Gene variation } & Protein change & \multicolumn{1}{c}{ Type of variant } \\
\hline 1 & Paternal & Exon 1 & c.[3G $>$ A $;$ c.124+1G $>C]$ & p.Met1Ile & $\begin{array}{l}\text { Start codon and donor } \\
\text { splicing site mutation }\end{array}$ \\
1 & Maternal & Exon 4 & c.509delG & p.Glu126Lysfs x 35 & $\begin{array}{l}\text { Frame-shift mutation } \\
\text { Nonsense mutation }\end{array}$ \\
\hline
\end{tabular}

A
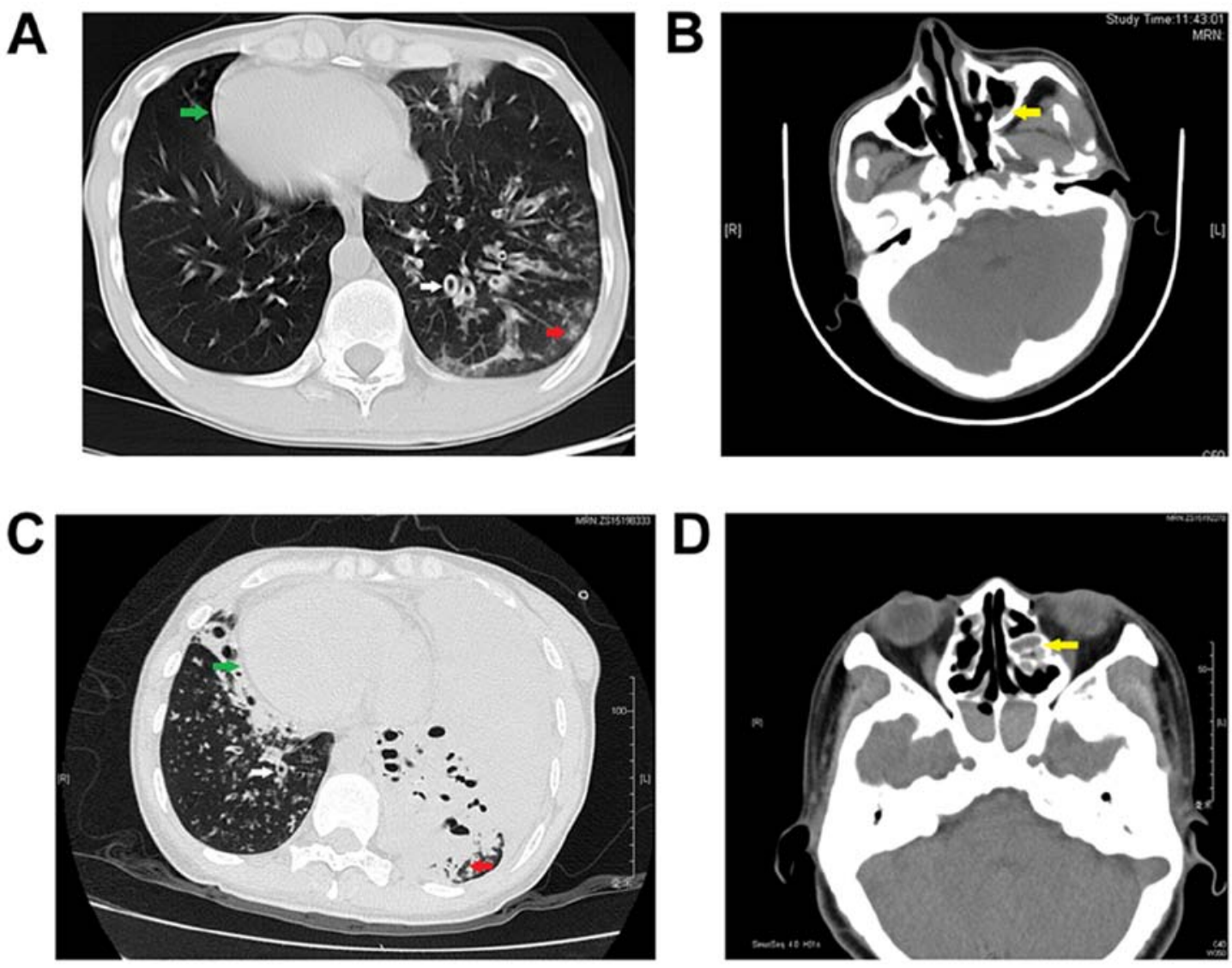

D

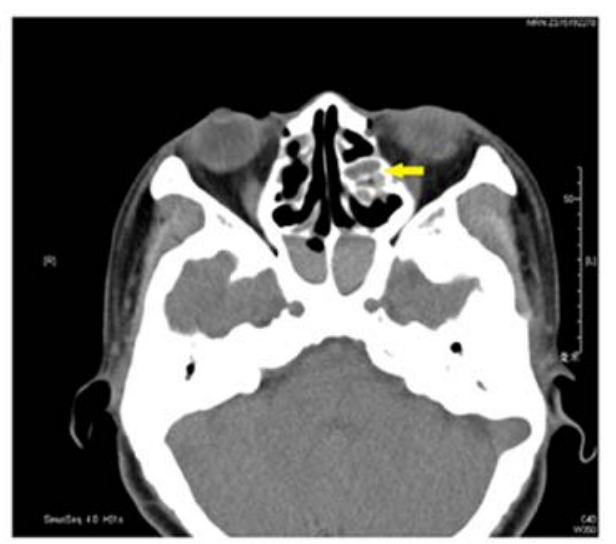

Figure 1. Chest and paranasal CT images of the two patients with dynein axonemal assembly factor 1 mutations. (A) Chest CT results revealed bronchiectasis and situs inversus and (B) paranasal CT results showed bilateral maxillary sinusitis in proband 1. (C) Chest CT results revealed bronchiectasis, a lung infection and situs inversus and (D) paranasal CT results showed bilateral ethmoid sinusitis in proband 2. White arrow, bronchiectasis. Red arrow, infection in the lung. Green arrow, cardiac situs inversus. Yellow arrow, maxillary sinusitis or ethmoid sinusitis. CT, computed tomography.

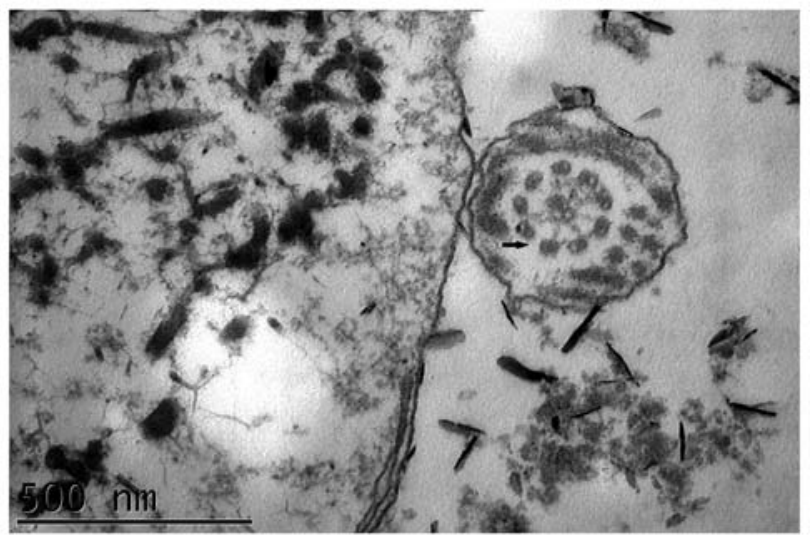

Figure 2. Transmission electron microscopy image of sperm flagella in proband 1 illustrating that both inner and outer dynein arms were defective (black arrow). tracheal intubation, she died due to a severe lung infection and poor heart function, which are the main causes of death for the majority of patients with PCD (11). Her parents were cousins and had no history of respiratory disease.

WES and Sanger sequencing. WES analysis showed that two of the seven patients carried DNAAF1 mutations. Proband 1 carried three point mutations (exon 4: c.509delG and exon 1: c. [3G $>A ; 124+1 G>C])$ and proband 2 was homozygous for exon 7: c.943A > T (Fig. 4, Table I). Information on all seven patients is listed in Table II. Out of the seven patients, TEM tests were conducted for five patients. The cilia of one patient was damaged due to severe infection. Another patient displayed normal cilia structure. The three other patients displayed IDA defects, central pair components defects or IDA and ODA defects, respectively. Among the four mutations identified, one 


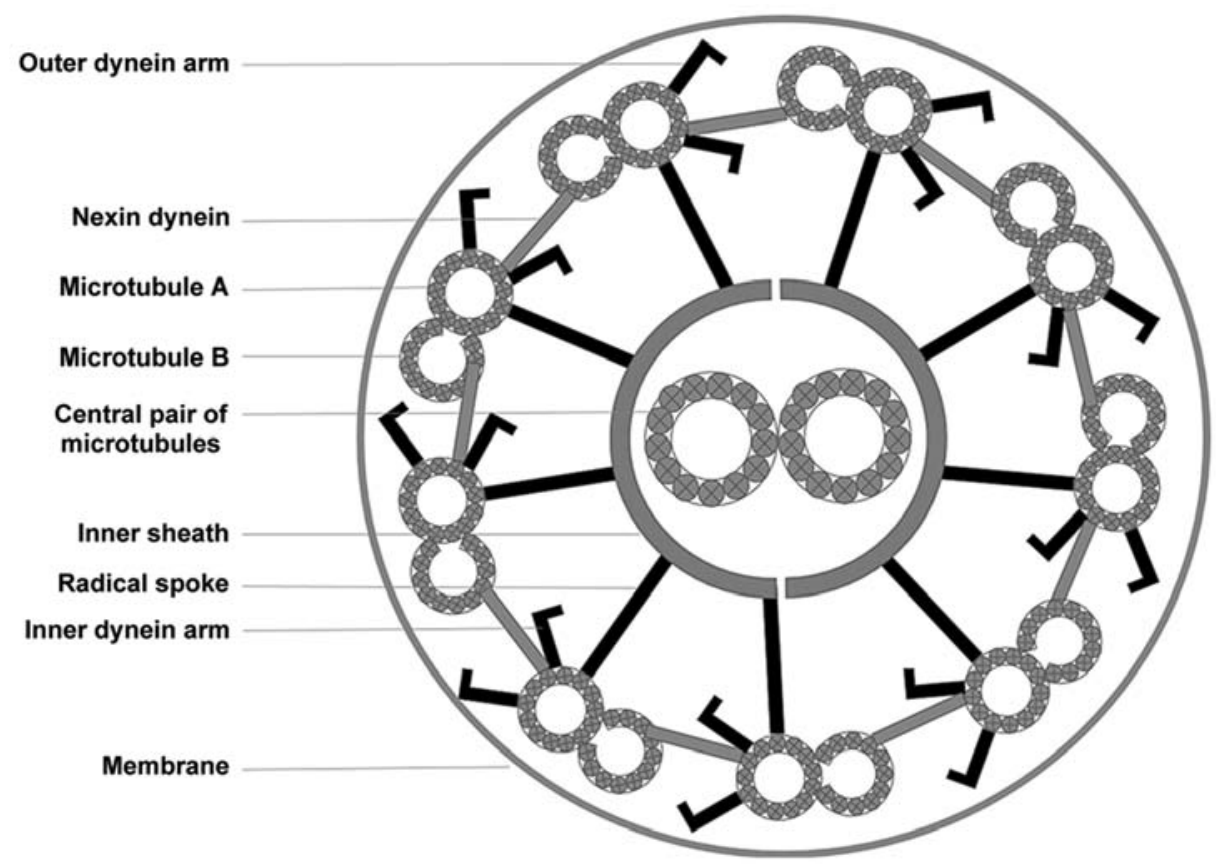

Figure 3. Schematic diagram of a cross-section of the ciliary axoneme with nine microtubule doublets surrounding the central pair of microtubules. The microtubules are interconnected via radial spokes, a nexin-dynein regulatory complex, and dynein arms.

(exon 4: c.509delG) was already registered in the dbSNP database as rs756239623. However, to the best of our knowledge, the present study was the first to identify the four mutations identified in patients with PCD. Sanger sequencing confirmed these mutations and revealed that proband 1 inherited exon 1 : c. [3G $>$ A;c. $124+1 \mathrm{G}>\mathrm{C}]$ from his father and exon 4: c.509delG from his mother. Proband 2 was found to have inherited the homozygous DNAAF1 mutation exon 7: c.943A>T from her parents, both of whom were heterozygous carriers (Fig. 5). WES and Sanger sequencing data are available on request.

Bioinformatics analysis. Bioinformatics analysis (data not shown) predicted that exon $1: \mathrm{c} .3 \mathrm{G}>\mathrm{A}$ in proband 1 would cause the amino acid substitution NP_848547.4:p.Met1Ile, leading to the loss of the DNAAF1 start codon. This was predicted to be 'damaging' by SIFT and PolyPhen-2, and the PVS1 strength level was found to be 'moderate'. Exon 1: c. $124+1 \mathrm{G}>\mathrm{C}$ is a splice-site mutation that was predicted by Human HSF and MES software to disrupt a highly conserved donor splice site in the mRNA and thus affect splicing. The PVS1 strength level of the variant containing this mutation was found to be 'very strong'. Together, exon 1: c. $3 \mathrm{G}>\mathrm{A}$ and c. $124+1 \mathrm{G}>\mathrm{C}$ were hypothesized to cause $D N A A F 1$ loss of function. Exon 4: c.509delG was predicted to cause a frameshift and create a premature stop codon (p.Glu126Lysfs x 35), leading to the loss of function of the protein in the other allele of proband 1 . The PVS1 strength level of this variant was also 'very strong'. Exon 7: c.943A $>$ T, carried by proband 2, is a nonsense mutation (p.Lys315x) that was predicted to create a premature stop codon (Fig. 6), and the variant with this mutation also had a 'very strong' PVS1 strength level. Finally, data for the healthy Chinese population was obtained from the 1000 Genomes Database and found that none of the aforementioned mutations had been registered. As the results of the functional analyses showed a 'significantly damaging' status for these mutations, it was proposed that these mutations may be the cause of the cilial defects in these two patients.

\section{Discussion}

Based on their structure and function, cilia can be subdivided into two categories: Motile and immotile. The airway epithelium contains mainly motile cilia, each of which consists of nine peripheral microtubule doublets and two central microtubules (12). IDA and ODA, which stretch out from the nine peripheral doublets, are multisubunit ATPase complexes. Their coordinated activation and inactivation generates a wave of beating cilia. ODA influences ciliary beat frequency and IDA determines the ciliary waveform (13). A deficiency in ODA and/or IDA is the main cause of PCD (5). It is estimated that $\sim 30 \%$ of PCD patients are both ODA- and IDA-deficient $(14,15)$. DNAAF1 mutations are responsible for cilia dysfunction in 4-5\% of PCD cases (7).

The DNAAF1 protein plays an essential role in the preassembly of IDA and ODA. DNAAF1 is mainly expressed in the airways, lungs and testicles in adult humans (7). These tissues and organs are covered with a ciliated epithelium or are rich in sperm flagella. DNAAF1 is distributed diffusely in the cytoplasm and cilia of ciliated cells and is concentrated at the spindle pole in mitotic cells. The DNAAFl gene is located on the chromosomal band 16p24.1 and produces two predicted transcripts, encoding two isoforms of 673 and 725 amino acid residues, respectively (16). Both isoforms contain six highly conserved N-terminal leucine-rich repeats (LRRs), a coiled coil, an LRR cap and a non-conserved proline-rich domain (16). The detailed mechanism of action of DNAAF1 is unclear; however, the evidence obtained thus far suggests that DNAAF1 is essential for the preassembly of dynein arms (17). 
A Proband 1, allele 1 c.509delG (reverse complementary sequence)

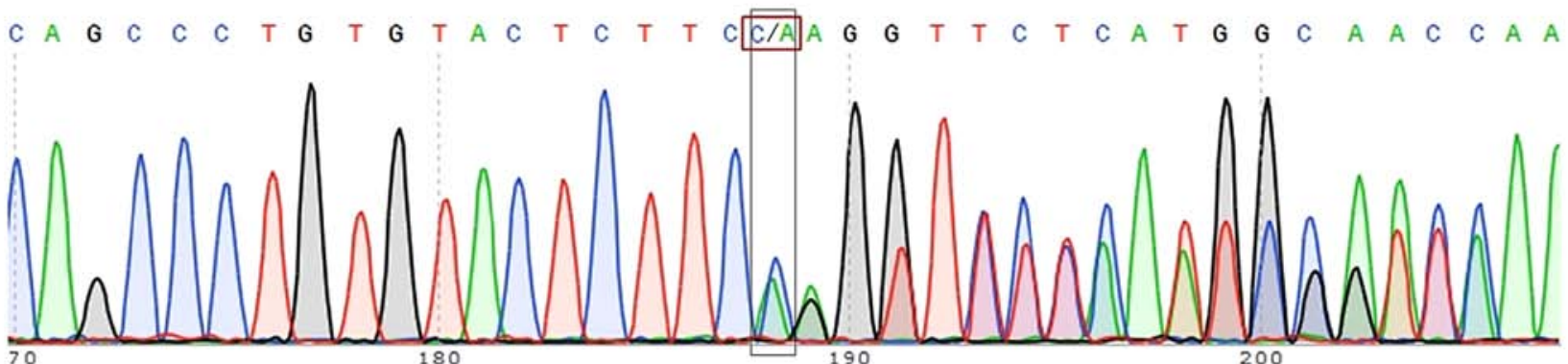

B Proband 1, allele 2 exon1:c.124+1G>C

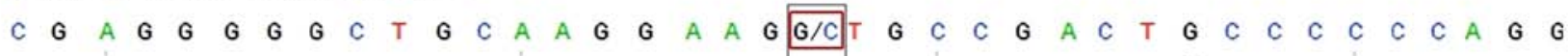

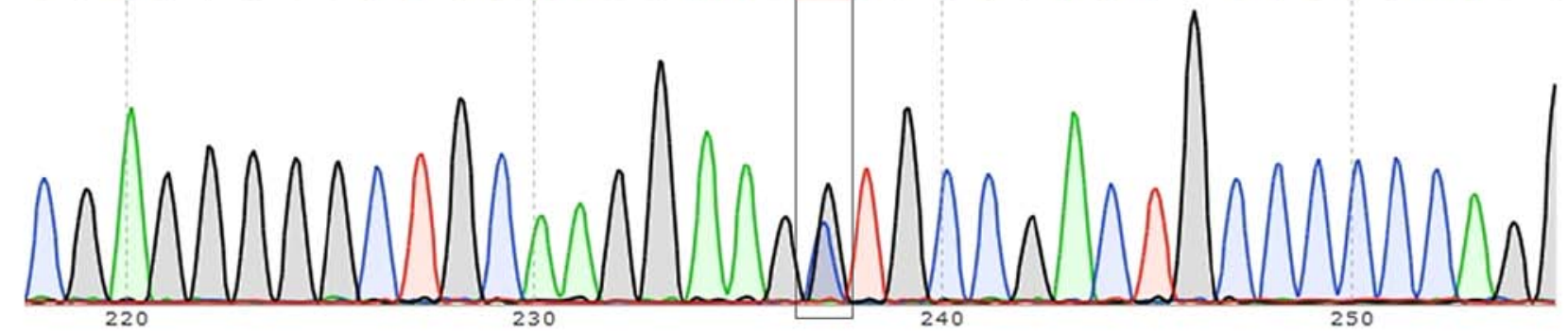

C Proband 1, allele 2 c.3G>A

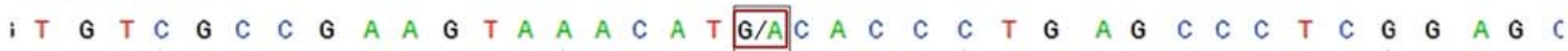

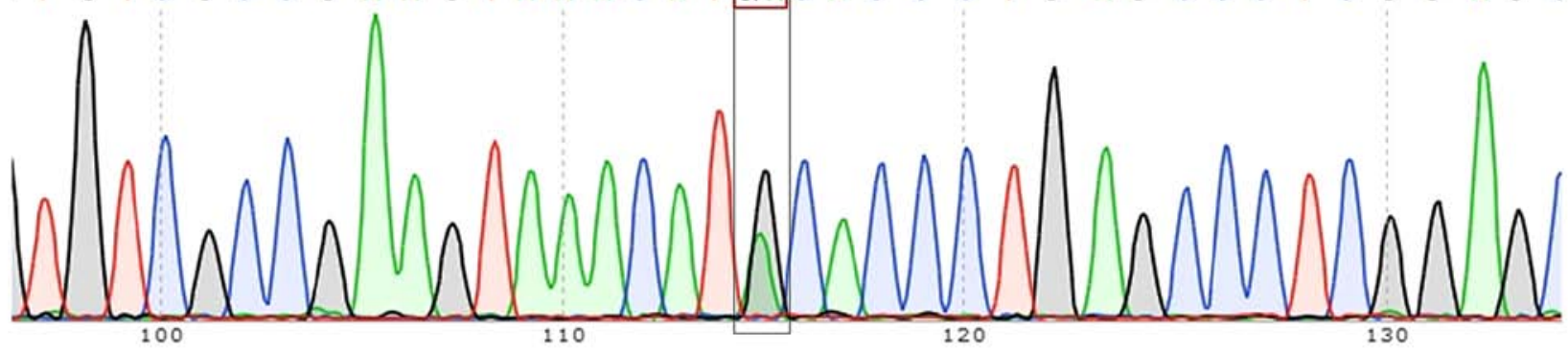

D Proband 2 c.943A>T

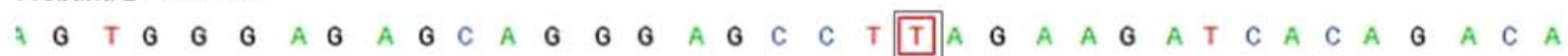

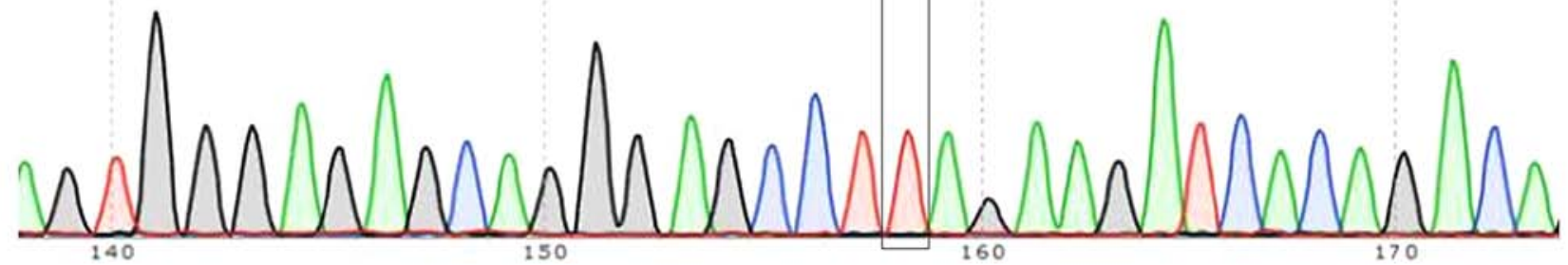

Figure 4. Sanger sequencing revealed mutations in two patients. (A) Exon 4: c.509delG (reverse complementary sequence), (B) exon 1: c.124+1G>C and (C) exon 1: c.3G $>\mathrm{A}$ in proband 1. (D) Exon 7: c.943A $>\mathrm{T}$ in proband 2.

The loss of DNAAFl results in the absence of ODA heavy chains dynein heavy chain (DNAH)5 and DNAH9, ODA intermediate chain dynein intermediate chain 2 and IDA light chain dynein axonemal light intermediate chain 1 in cilia $(6,18)$. Instead, these dynein arm components accumulate in the cytoplasm as cilium assembly is a continuous process (18). These observations explain why both ODA and IDA defects are present in individuals with $D N A A F 1$ mutations.

A total of 15 causative DNAAF1 mutations have been reported thus far, in 13 PCD patients from ten families
(Table III) $(6,7,17)$. Meanwhile, the present study describes three novel DNAAF1 mutations in two Chinese Han patients with PCD. TEM analysis showed that proband 1, a 37-year old patient with ODA and IDA defects in his sperm flagella, inherited compound heterozygous mutations from his parents. The maternal allele included c.509delG, which introduced a frameshift and created a premature stop codon (p.Glu126Lysfs x 35). As a result, $75 \%$ of the normal amount of DNAAF1 protein was lost, resulting in a partial, but substantial, loss of function of DNAAF1. The paternal 
Table II. Clinical data of all patients with primary ciliary dyskinesia.

\begin{tabular}{|c|c|c|c|c|c|c|}
\hline $\begin{array}{l}\text { Subject } \\
\text { number }\end{array}$ & $\begin{array}{l}\text { Age, } \\
\text { years }\end{array}$ & Sex & Chest CT & Paranasal CT & $\begin{array}{c}\text { Pulmonary function } \\
\text { test }\end{array}$ & TEM test \\
\hline 1 & 32 & Male & $\begin{array}{l}\text { Bronchiectasis in } \\
\text { multi-lobes of the lung } \\
\text { and situs inversus }\end{array}$ & $\begin{array}{l}\text { Bilateral maxillary } \\
\text { sinusitis, ethmoid } \\
\text { sinusitis }\end{array}$ & $\begin{array}{l}\text { FEV1: } 1.80 \mathrm{~L}, \mathrm{FEV} 1 / \\
\text { pred: } 53.1 \%, \mathrm{FEV} 1 / \\
\text { FVC: } 63.43 \%\end{array}$ & $\begin{array}{l}\text { IDA and ODA } \\
\text { defects }\end{array}$ \\
\hline 2 & 37 & Female & $\begin{array}{l}\text { Bronchiectasis, severe } \\
\text { lung infections and } \\
\text { situs inversus }\end{array}$ & $\begin{array}{l}\text { Bilateral maxillary } \\
\text { sinusitis, ethmoid } \\
\text { sinusitis, sphenoid } \\
\text { sinusitis and frontal } \\
\text { sinusitis }\end{array}$ & $\begin{array}{l}\text { FEV1: } 0.77 \text { L, FEV1/ } \\
\text { pred: } 23.78 \%, \text { FEV1/ } \\
\text { FVC: } 59.58 \%\end{array}$ & $\begin{array}{l}\text { Nasal epithelium } \\
\text { cilia damaged } \\
\text { because of } \\
\text { severe infection }\end{array}$ \\
\hline 3 & 41 & Female & $\begin{array}{l}\text { Bronchiectasis, and } \\
\text { situs inversus, the } \\
\text { middle lobe of left } \\
\text { lung resected because } \\
\text { of bronchiectasis } \\
\text { hemorrhage }\end{array}$ & $\begin{array}{l}\text { Bilateral maxillary } \\
\text { sinusitis, ethmoid } \\
\text { sinusitis, sphenoid } \\
\text { sinusitis and frontal } \\
\text { sinusitis }\end{array}$ & $\begin{array}{l}\text { FEV1: } 0.71 \mathrm{~L} ; \mathrm{FEV} 1 / \\
\text { pred: } 28.80 \% \text {; FEV1/ } \\
\text { FVC: } 48.39 \%\end{array}$ & $\begin{array}{l}\text { Normal ODA } \\
\text { and IDA } \\
\text { structures }\end{array}$ \\
\hline 4 & 8 & Male & $\begin{array}{l}\text { Bronchiectasis, and } \\
\text { situs inversus }\end{array}$ & $\begin{array}{l}\text { Bilateral ethmoid } \\
\text { sinusitis, sphenoid } \\
\text { sinusitis and frontal } \\
\text { sinusitis }\end{array}$ & $\begin{array}{l}\text { FEV1: } 0.70 \text { L; FEV1/ } \\
\text { pred: } 33.92 \% \text {; FEV1/ } \\
\text { FVC: } 89.44 \%\end{array}$ & $\begin{array}{l}\text { Refused TEM } \\
\text { analysis }\end{array}$ \\
\hline 5 & 28 & Male & $\begin{array}{l}\text { Bronchiectasis, and } \\
\text { situs inversus }\end{array}$ & Paranasal sinusitis & $\begin{array}{l}\text { FEV1: } 2.83 \mathrm{~L} ; \mathrm{FEV} 1 / \\
\text { pred: } 78.98 \% \text {; FEV1/ } \\
\text { FVC: } 76.65 \%\end{array}$ & $\begin{array}{l}\text { Central pair } \\
\text { components } \\
\text { defect or } \\
\text { dislocation }\end{array}$ \\
\hline 6 & 34 & Male & $\begin{array}{l}\text { Bilateral bronchiectasis, } \\
\text { and situs inversus }\end{array}$ & Paranasal sinusitis & $\begin{array}{l}\text { FEV1: } 2.57 \mathrm{~L} ; \text { FEV1/ } \\
\text { pred: } 76.24 \% \text {; FEV1/ } \\
\text { FVC: } 69.48 \%\end{array}$ & $\begin{array}{l}\text { Refused TEM } \\
\text { analysis }\end{array}$ \\
\hline 7 & 18 & Female & $\begin{array}{l}\text { Bronchiectasis in } \\
\text { multi-lobes, and } \\
\text { situs inversus }\end{array}$ & Paranasal sinusitis & $\begin{array}{l}\text { Not be able to } \\
\text { perform PFT }\end{array}$ & IDA defects \\
\hline
\end{tabular}
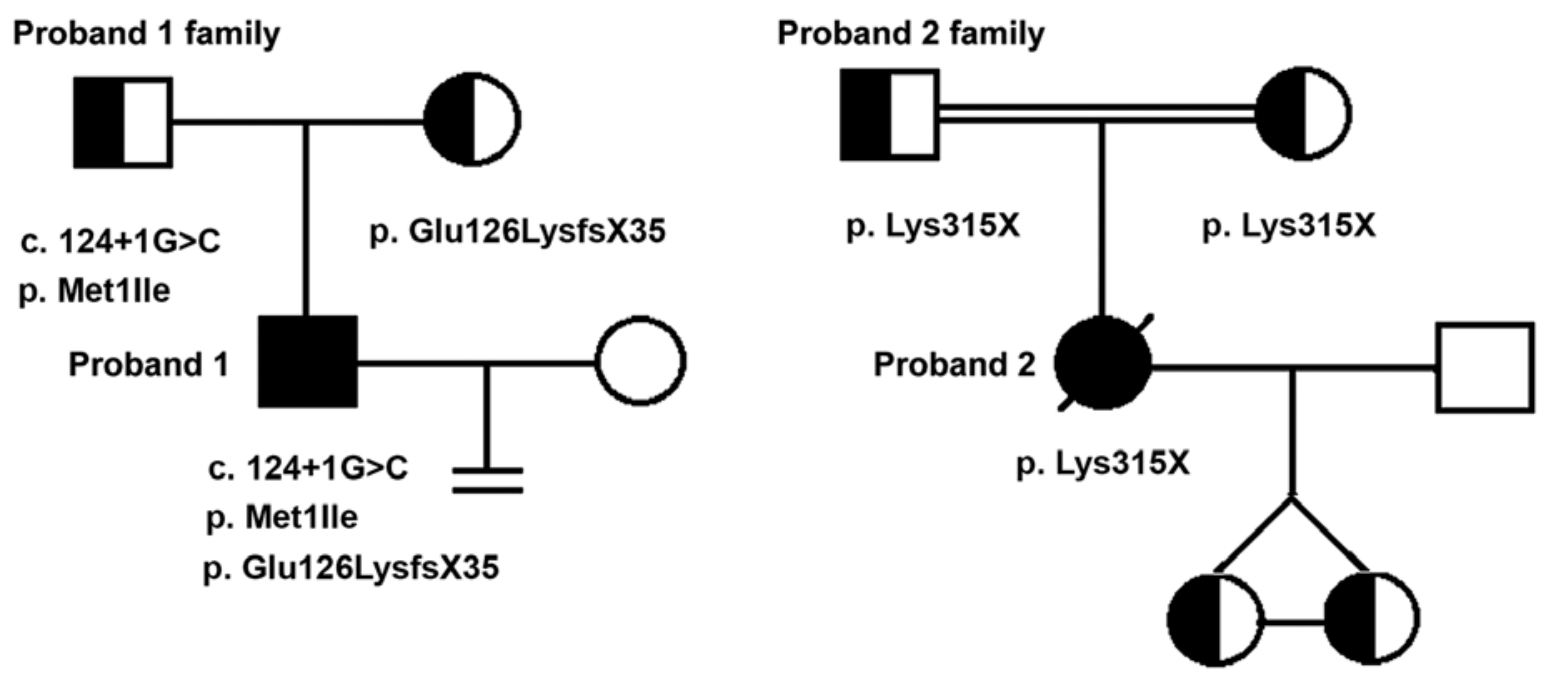

Figure 5. Proband 1 inherited exon 1: c.3G $>$ A and exon 1: c.124+1G $>$ C from his father and exon 4: c.509delG from his mother and had no children. Proband 2 inherited a homozygous dynein axonemal assembly factor 1 mutation, exon 7: c.943A $>\mathrm{T}$, from her heterozygous parents and had two daughters by artificial fertilization. The double bar indicates that the proband's parents have the same grandfather. 
Table III. Dynein axonemal assembly factor 1 mutations in patients with primary ciliary dyskinesia.

\begin{tabular}{|c|c|c|c|c|c|}
\hline Author, year & $\begin{array}{l}\text { Number } \\
\text { of cases }\end{array}$ & DNA change & $\begin{array}{l}\text { Location on } \\
D N A A F 1\end{array}$ & Protein change & (Refs.) \\
\hline Loges et al, 2009 & 1 & {$\left[\mathrm{c} .1349 \_1350\right.$ insC $^{\mathrm{a}}$} & Exon 8 & p.Pro451Alafs x 5 & (6) \\
\hline Loges et al, 2009 & 1 & {$[11 \mathrm{~kb}$ del $]+[640 \mathrm{~kb} \mathrm{del}]^{\mathrm{b}}$} & $\begin{array}{l}16 \mathrm{q} 24.1 / 16 \mathrm{q} 23.3- \\
16 \mathrm{q} 24.1\end{array}$ & $\begin{array}{l}\text { Loss of protein DNAAF1, } \\
\text { HSDL1, et al }\end{array}$ & (6) \\
\hline Loges et al, 2009 & 1 & {$[\mathrm{c} .811 \mathrm{C}>\mathrm{T}]+[220 \mathrm{~kb} \mathrm{del}]^{\mathrm{b}}$} & Exon 6/16q24.1 & $\begin{array}{l}\text { p.Arg } 271 \mathrm{x} / \text { Loss of } \\
\text { protein DNAAF1, } \\
\text { HSDL1, et al }\end{array}$ & (6) \\
\hline $\begin{array}{l}\text { Duquesnoy et al, } \\
2009\end{array}$ & 1 & {$[\mathrm{c} .792 \mathrm{C}>\mathrm{A}]+[\mathrm{c} .508 \mathrm{dupG}]^{\mathrm{b}}$} & Exon $6 / 4$ & $\begin{array}{l}\text { p.Tyr264 x /p.Glu170Glyfs } \\
\text { x } 10\end{array}$ & (7) \\
\hline $\begin{array}{l}\text { Duquesnoy et al, } \\
2009\end{array}$ & 1 & {$[\mathrm{c} .115 \mathrm{dupT}]+\left[\mathrm{c} .1300 \_1322 \mathrm{del} 23 \mathrm{bp}\right]^{\mathrm{b}}$} & Exon $1 / 8$ & $\begin{array}{l}\text { p.Cys39Leufs x 44/p. } \\
\text { Gly434Profsx } 4\end{array}$ & (7) \\
\hline $\begin{array}{l}\text { Duquesnoy et al, } \\
2009\end{array}$ & 1 & $\begin{array}{l}\text { [c.1198_1199insTCGC]+ } \\
{\left[\mathrm{c} .124+1536 \_353-2102 \mathrm{del} 5376 \mathrm{bp}\right]^{\mathrm{b}}}\end{array}$ & Exon 8/ 2-3 & $\begin{array}{l}\text { p.Pro400Leufs x 6/p. } \\
\text { Glu42_Lys } 117 \mathrm{del}\end{array}$ & $(7)$ \\
\hline $\begin{array}{l}\text { Duquesnoy et al, } \\
2009\end{array}$ & 2 & {$[\mathrm{c} .524 \mathrm{~T}>\mathrm{G}]^{\mathrm{a}}$} & Exon 4 & p.Leu175Arg & (7) \\
\hline $\begin{array}{l}\text { Hartill, et al, } \\
2018\end{array}$ & 3 & {$[\mathrm{c} .281 \mathrm{delA}]+[\mathrm{c} .1484 \mathrm{delC}]^{\mathrm{b}}$} & Exon $3 / 8$ & $\begin{array}{l}\text { Lys95Asnfs x 14/ } \\
\text { Pro495Glnfs x } 40\end{array}$ & $(17)$ \\
\hline $\begin{array}{l}\text { Hartill, et al, } \\
2018\end{array}$ & 1 & {$[\mathrm{c} .1484 \mathrm{delC}]^{\mathrm{a}}$} & Exon 8 & Pro495Glnfs x 40 & $(17)$ \\
\hline $\begin{array}{l}\text { Hartill, et al, } \\
2018\end{array}$ & 1 & 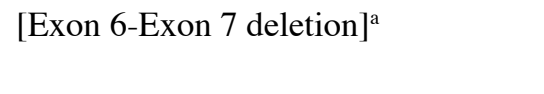 & Exon 6-7 & Incomplete protein & $(17)$ \\
\hline
\end{tabular}

${ }^{\mathrm{a} H o m o z y g o u s ~ m u t a t i o n, ~}{ }^{\mathrm{b}}$ heterozygous mutation.

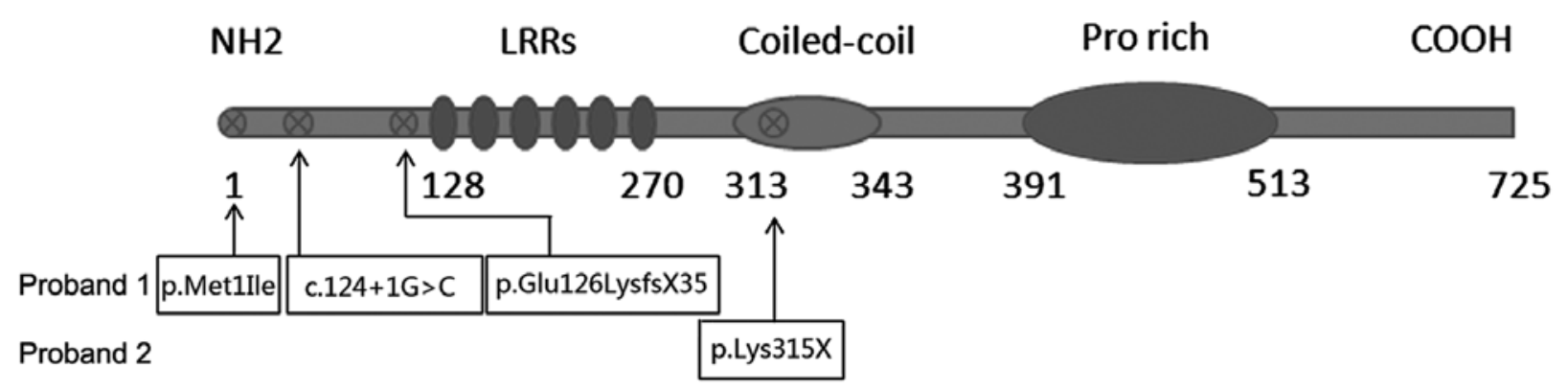

Figure 6. Dynein axonemal assembly factor 1 protein mutation positions.

allele included a missense point mutation $(\mathrm{c} .3 \mathrm{G}>\mathrm{A})$ and a splice-site mutation $(\mathrm{c} .124+1 \mathrm{G}>\mathrm{C})$. The missense mutation, which resulted in the amino acid substitution p.Met1Ile, is a start codon mutation, which prevented the transcription of the entire DNAAF1 gene and was predicted to be damaging by SIFT and PolyPhen-2. However, the splice-site mutation disrupted a highly conserved donor splice site at the 5' end of the mRNA and affected the correct splicing of exon 1. HSF and MES algorithms predicted that the effect of this mutation was possibly severe damage. A similar donor splice-site mutation has been reported in mouse $D N A A F 1$, leading to the absence of the entire exon 4 sequence in the transcript (19). On the basis of these observations, it was propose that both of these mutations contributed to the loss of DNAAF1 protein function in this proband.
Proband 2, who was a female patient born to consanguineous parents, carried a homozygous nonsense point mutation (c.943A $>$ T), which led to a premature translation stop codon at p.315, resulting in the deletion of half of the normal protein. This was expected to result in a complete loss of function of the DNAAF1 protein. Due to the severe infection in her airways, there were not enough cilia to examine in the biopsy samples collected from her nose or bronchi. Hence, her cilial phenotype remains undetermined. Nevertheless, genetic analysis confirmed the PCD diagnosis in this patient. Unfortunately, this patient died due to the severe lung infection and poor lung and heart function, which are a common complications of chronic lung disease (20). Compared with mutations in the human orthologue of medaka kintoun gene, another PCD-associated gene that can also cause ODA and 
IDA defects (21), patients with $D N A A F 1$-mutant PCD tend to have more severe cell defects $(6,21)$. For example, both of the patients in the present study developed bronchiectasis and infection in both lungs, against a background of situs inversus and infertility. Infertility is another common complication of PCD, especially in male patients. The immobility of sperm flagella can cause an impairment in or the complete absence of the ability of the flagella to swim, which ultimately results in male infertility (22). Since coordinated ciliary beating, in conjunction with muscle contractions, plays a role in directing the oocyte through the fallopian tubes to the uterus, PCD is also thought to be an important cause of female subfertility (23). However, accumulating evidence has shown that, compared with male patients, female patients with PCD have a greater chance of achieving spontaneous conception and fertility (24). All reported female patients with $D N A A F 1$ mutations have not had offspring naturally $(6,7,17)$; however, due to the small number of known patients, an association between DNAAF1 mutations and female infertility has not been established. Fortunately, most patients with PCD have healthy offspring with the help of assisted reproductive technology (22).

Aside from ODA and IDA, DNAAF1 also contributes to the construction of the axoneme. Inactivation of DNAAF1 expression significantly reduces the brush border or decreases cilial length in the proximal tubule epithelium cell line HK-2 (16). Considering that normal human kidneys do not contain motile cilia or dynein arms, these data suggest that $D N A A F 1$ mutation interrupts the construction of the cilial axoneme backbone instead of dynein arms.

DNAAF1 may play a role in the regulation of gene expression. Miao et al (25) evaluated the mRNA expression profiles of 227 neural tube closure-associated genes in a patient with DNAAF1 mutations and neural tube defects and healthy controls. The results demonstrated that three genes were upregulated and 19 were downregulated in this patient. Moreover, changes in DNAAF1 expression levels led to a corresponding change in the expression levels of left-right patterning genes and the sonic hedgehog signaling-associated genes, Lefty1, Lefty 2 and Gli2, in NE-4C neuroectodermal stem cells. Nonetheless, it remains unknown whether DNAAF1 regulates gene expression in human airways.

PCD is a genetically heterogeneous disorder, and the genetic causes of $\sim 30 \%$ of PCD cases remain to be elucidated (5). Patients with DNAAF1 mutations constitute only a small proportion of all PCD cases; however, DNAAF1 mutation usually causes the misalignment of both ODA and IDA and thus induces severe clinical symptoms. The present study reported two patients with DNAAF1 mutations, one of whom died due to severe lung infection and poor lung and heart function. An effective strategy to treat genetic defects in PCD patients has not yet been devised. The injection of $D N A A F 1$ mRNA into DNAAF1-mutant zebrafish can reverse their cilial defects, but it remains unclear whether exogenous DNAAF1 can promote cilial motility in humans (16). To further explore the role of DNAAF1 in ciliated epithelial cells, as well as the mechanism underlying bronchiectasis, a DNAAF1 mutant mouse model should be established in future studies, which could be used to investigate novel treatment strategies for targeting DNAAF1.

\section{Acknowledgements}

Not applicable.

\section{Funding}

The present study was supported by the National Natural Science Foundation of China Key grant (grant nos. 81630001, 81490533, 81770055, 81500026, 81570028 and 81600056), the State Key Basic Research Program Project (grant no. 2015CB553404), the Shanghai Science and Technology Committee (grant nos. 15DZ1930600, 15DZ1930602 and 16ZR1405700) and Shanghai Municipal Commission of Health and Family Planning (grant no. 201540370).

\section{Availability of materials and data}

The datasets used and/or analyzed during the present study are available from the corresponding author on reasonable request.

\section{Authors' contributions}

LZ carried out the molecular genetic studies and wrote the original draft. ZL, CC carried out the molecular and genetic bioinformatic studies. CD enrolled the subjects and conducted their treatments, performed the literature searching and analysis. LG, YinS and FZ participated in phenotyping and clinical data collection. YuaS designed this study, wrote, reviewed and edited the final version of the manuscript. All authors read and approved the final manuscript.

\section{Ethics approval and consent to participate}

The present study was approved by the Ethics Committee of Zhongshan Hospital Qingpu Branch (approval no. 2018-12; Shanghai, China). All participants or their guardians provided written informed consent.

\section{Patient consent for publication}

Informed written consent was obtained from the patient or their guardian for the publication of this case report and any accompanying images.

\section{Competing interests}

The authors declare that they have no competing interests.

\section{References}

1. Olm MA, Caldini EG and Mauad T: Diagnosis of primary ciliary dyskinesia. J Bras Pneumol 41: 251-263, 2015 (In English, Portuguese).

2. Frommer A, Hjeij R, Loges NT, Edelbusch C, Jahnke C, Raidt J, Werner C, Wallmeier J, Große-Onnebrink J, Olbrich $\mathrm{H}$, et al: Immunofluorescence analysis and diagnosis of primary ciliary dyskinesia with radial spoke defects. Am J Respir Cell Mol Biol 53: 563-573, 2015.

3. Brown J and Witman G: Cilia and Diseases. Bioscience 64: 1126-1137, 2014. 
4. Cao Y, Shao C, Song Y, Bai C and He L: Clinical analysis of patients with primary ciliary dyskinesia in mainland China. Clin Respir J 10: 765-771, 2016.

5. Leigh MW, Horani A, Kinghorn B, O'Connor MG, Zariwala MA and Knowles MR: Primary Ciliary Dyskinesia (PCD): A genetic disorder of motile cilia. Transl Sci Rare Dis 4: 51-75, 2019.

6. Loges NT, Olbrich H, Becker-Heck A, Häffner K, Heer A, Reinhard C, Schmidts M, Kispert A, Zariwala MA, Leigh MW, et al: Deletions and point mutations of LRRC50 cause primary ciliary dyskinesia due to dynein arm defects. Am J Hum Genet 85: 883-889, 2009.

7. Duquesnoy P, Escudier E, Vincensini L, Freshour J, Bridoux AM, Coste A, Deschildre A, de Blic J, Legendre M, Montantin G, et al: Loss-of-function mutations in the human ortholog of Chlamydomonas reinhardtii ODA7 disrupt dynein arm assembly and cause primary ciliary dyskinesia. Am J Hum Genet 85: 890-896, 2009 .

8. Marshall CR, Scherer SW, Zariwala MA, Lau L, Paton TA, Stockley T, Jobling RK, Ray PN, Knowles MR; FORGE Canada Consortium, Hall DA, et al: Whole-exome sequencing and targeted copy number analysis in primary ciliary dyskinesia. G3 (Bethesda) 5: 1775-1781, 2015.

9. Desmet FO, Hamroun D, Lalande M, Collod-Béroud G, Claustres M and Béroud C: Human Splicing Finder: An online bioinformatics tool to predict splicing signals. Nucleic Acids Res 37: e67, 2009.

10. Yeo $\mathrm{G}$ and Burge $\mathrm{CB}$ : Maximum entropy modeling of short sequence motifs with applications to RNA splicing signals. J Comput Biol 11: 377-394, 2004.

11. Kennedy MP, Omran H,Leigh MW, Dell S, Morgan L, Molina PL, Robinson BV, Minnix SL, Olbrich H, Severin T, et al: Congenital heart disease and other heterotaxic defects in a large cohort of patients with primary ciliary dyskinesia. Circulation 115 2814-2821, 2007.

12. Satir P and Christensen ST: Overview of structure and function of mammalian cilia. Annu Rev Physiol 69: 377-400, 2007.

13. Fliegauf M, Benzing $\mathrm{T}$ and Omran $\mathrm{H}$ : When cilia go bad: Cilia defects and ciliopathies. Nat Rev Mol Cell Biol 8: 880-893, 2007.

14. Jorissen M, Willems T, Van der Schueren B, Verbeken E and De Boeck K: Ultrastructural expression of primary ciliary dyskinesia after ciliogenesis in culture. Acta Otorhinolaryngol Belg 54: 343-356, 2000.
15. Papon JF, Coste A, Roudot-Thoraval F, Boucherat M, Roger G, Tamalet A, Vojtek AM, Amselem S and Escudier E: A 20-year experience of electron microscopy in the diagnosis of primary ciliary dyskinesia. Eur Respir J 35: 1057-1063, 2010.

16. van Rooijen E, Giles RH, Voest EE, van Rooijen C, Schulte-Merker S and van Eeden FJ: LRRC50, a conserved ciliary protein implicated in polycystic kidney disease. J Am Soc Nephrol 19: 1128-1138, 2008

17. Hartill VL, Hoek G, Patel MP, Little R, Watson CM, Berry IR, Shoemark A,Abdelmottaleb D, Parkes E, Bacchelli C, et al: DNAAF1 links heart laterality with the AAA1 ATPase RUVBL1 and ciliary intraflflagellar transport. Hum Mol Genet 27: 529-545, 2018.

18. Fliegauf M, Olbrich H, Horvath J, Wildhaber JH, Zariwala MA, Kennedy M,Knowles MR and Omran H: Mislocalization of DNAH5 and DNAH9 in respiratory cells from patients with primary ciliary dyskinesia. Am J Respir Crit Care Med 171: 1343-1349, 2005.

19. Ha S, Lindsay AM, Timms AE and Beier DR: Mutations in DNAAF1 and LRRC48 cause hydrocephalus, laterality defects, and sinusitis in mice. G3 (Bethesda) 6: 2479-2487, 2016.

20. Lobo LJ, Zariwala MA and Noone PG: Primary ciliary dyskinesia. QJM 107: 691-699, 2014.

21. Omran H, Kobayashi D, Olbrich H, Tsukahara T, Loges NT, Hagiwara $\mathrm{H}$, Zhang Q, Leblond G, O'Toole E, Hara C, et al: $\mathrm{Ktu} / \mathrm{PF} 13$ is required for cytoplasmic pre-assembly of axonemal dyneins. Nature 456: 611-616, 2008.

22. Sha Y, Ding L and Li P: Management of primary ciliary dyskinesia/Kartagener's syndrome in infertile male patients and current progress in defining the underlying genetic mechanism. Asian J Androl 16: 101-106, 2014.

23. Lyons RA, Saridogan E and Djahanbakhch O: The reproductive signifificance of human Fallopian tube cilia. Hum Reprod Update 12: 363-372, 2006.

24. Raidt J, Werner C, Menchen T, Dougherty GW, Olbrich H, Loges NT, Schmitz R, Pennekamp P and Omran H: Ciliary function and motor protein composition of human fallopian tubes. Hum Reprod 30: 2871-2880, 2015.

25. Miao C, Jiang Q, Li H, Zhang Q, Bai B, Bao Y and Zhang T: Mutations in the motile cilia gene DNAAF1 are associated with neural tube defects in humans. G3 (Bethesda) 6: 3307-3316, 2016.

This work is licensed under a Creative Commons

Attribution-NonCommercial-NoDerivatives 4.0

International (CC BY-NC-ND 4.0) License. 